\title{
Tacna y su relación histórica con la caña hueca
}

\author{
Tacna and its historical relationship with the hollow reed
}

ORCID: 0000-0003-2825-6289

\section{RESUMEN}

El presente trabajo de indagación y recopilación tuvo como objetivo mostrar el valor cultural de la caña hueca, cuyo nombre científico es Arundo donax, y su relación con Tacna. También se mostraron evidencias de la existencia de la caña en la emoción del antiguo tacneño, por parte de representantes del arte y la cultura en nuestra región, quienes al igual que con otros recursos naturales (como las buganvillas) reconocieron su influencia. Se revisó la situación de las tierras de cultivo durante la época colonial en el Perú y parte de la republicana. Asimismo, se rememoró algunos acontecimientos de la época del cautiverio, conjuntamente con toda la barbarie vivida. Se reforzaron las características inherentes de la caña hueca, como su resistencia a ser eliminada fácilmente de los suelos. Y que a pesar de ser considerada una planta invasiva en muchas partes del mundo, al igual que el tacneño durante el cautiverio, resistió los embates del tiempo, lo que se lo debe en gran parte a sus raíces llamadas rizomas. Por otro lado, se tuvieron en cuenta los usos de la caña, que en el viejo mundo se venía haciendo de manera paralela a la culminación del cautiverio; asimismo, sus usos tradicionales hasta los realizados en la época contemporánea. Además, se exploraron antecedentes de proyectos referentes a la intervención de la caña en la vida del hombre de hoy en las zonas rurales.

Palabras clave: Acequia, caña, rizoma.

\section{ABSTRACT}

The aim of the research was to show the cultural value of the hollow reed, whose scientific name is Arundo donax, and its relationship with Tacna. The evidence of the existence of hollow reed in the emotion of the ancient Tacna people was also shown by representatives of the art and culture in our region, who recognized its influence, as with other natural resources (such as bougainvilleas). The situation of the cultivated lands during the colonial period in Peru and part of the republican period was reviewed. Likewise, some events of the time of captivity were recalled, along with all the barbarism experienced. The inherent characteristics of hollow reed were reinforced, such as its resistance to being easily removed from the soil. And that spite being considered an invasive plant in many parts of the world, it resisted the onslaught of time, just like the tacneño during captivity, which is due to its roots called rhizomes. Furthermore, the uses of hollow reed in Europe, parallel to captivity, were taken into account; likewise, its traditional and contemporary uses. In addition, antecedents of projects related to the intervention of hollow reedin the life of today's man in rural areas were explored.

Keywords: Irrigation ditch, hollow reed, rhizome.

${ }^{1}$ Investigador independiente. Tacna, Perú. Ingeniero en Informática y Sistemas. E-mail: renealanoca@gmail.com 


\section{INTRODUCCIÓN}

Desde el comienzo de las civilizaciones, el hombre primitivo que apareció durante el amanecer del mundo notó que en la huella de su puño sobre greda húmeda podía quedar almacenada una pequeña cantidad de agua. Posteriormente, necesitó palos y piedras para la construcción de su casa y su defensa; del mismo modo, utilizó pieles de animales para su abrigo personal; comenzó a relacionarse más con la naturaleza, empleándola como medio para satisfacer sus necesidades básicas y secundarias. Como en todo proceso folklórico, las generaciones fueron eligiendo formas y técnicas que terminaron por satisfacer a todos y hacerse tradicionales. Cada país y región tiene las suyas.

Si casi "todo el conocimiento humano puede hallarse en libros y bibliotecas" y es posible disponer de ellas "del conjunto de adquisiciones logradas por las generaciones precedentes, que constituyen la herencia inestimable del pasado", el archivo personal que es algo más amplio $\mathrm{y}$ permanente que la clasificación de material para una investigación es en alguna medida una especie de acumulador y depósito de los conocimientos personales.

Al hablar de la organización del material, podemos estar haciendo mención a la organización del material para una investigación, o a la organización del material de investigación. Los dos aspectos son necesarios: el primero para cada investigación concreta, el segundo para ir archivando las ideas, las reflexiones y los hechos que el investigador social va "depositando" en el transcurso de su vida. Este archivo es de utilidad tanto para el investigador social, como para un trabajador social y el sólo "hecho de llevarlo" es ya producción intelectual (Egg, 1978, p.73).

En Tacna, no se le ha reconocido aún a la caña hueca como el material que identifique la artesanía de la región, a comparación otras regiones como Ayacucho o Cusco. Nuestra ciudad tiene ventajas al encontrarse en una zona comercial y de frontera. Sin embargo, no se cuenta con una tradición en artesanía, cuyos productos puedan ser vendidos al exterior, demostrando la identidad de la región de Tacna como el caso de la caña hueca, fibra vegetal de los callejones de Tacna de antaño.

\section{CAÑA HUECA}

Es una planta de las familias gramíneas, con tallo leñoso, hueco, flexible y de tres a cuatro metros de altura, hojas anchas, un tanto ásperas, y flores en panojas muy ramosas. "Parece ser originaria del sur de Asia, y se ha extendido al área mediterránea y norte de África a lo largo de ríos y acequias. Su posterior introducción a América a inicios del siglo XIX" (Bell, 1997, p. 104). En el Perú no precisan fechas exactas.

\section{Figura 1}

Países del mundo que presentan Arundo donax

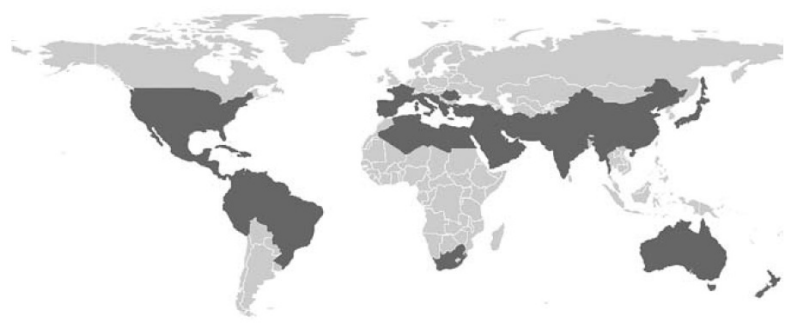

Fuente: Bases para el manejo y control de Arundo donax L. (Caña común).

La caña hueca (Arundo Donax) se desarrolla en zonas riparias y suelos con una cierta humedad. Se encuentra ubicada en casi toda la costa y los valles de nuestro país, confundiéndose en algunos lugares con el carrizo (Phragmites Australis).

Etimológicamente, Arundo es el nombre genérico que proviene del latín antiguo y que significa "caña" y donax es el nombre latino y griego de una especie de "caña", que en principio se usó como nombre genérico, pero que resultó ser sinónimo de Arundo. 


\section{Figura 2}

Manchade Cañas

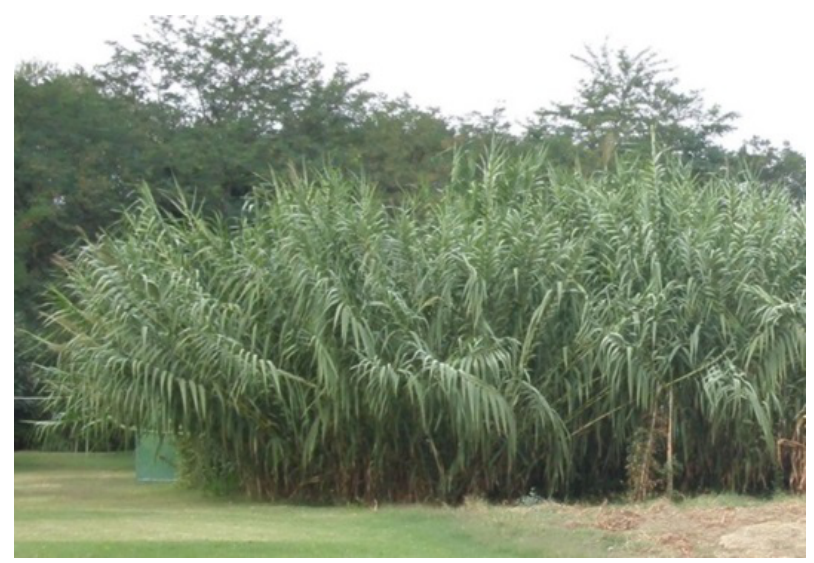

Fuente: Fotografía propia

\section{¿POR QUE INVESTIGAR UNA CAÑA?}

Investigar un recurso natural no es ser menester solo de científicos, sino que es una necesidad humana para poder interrelacionarse con el medio ambiente. Es importante encontrar, si fuese posible, el contrapunto donde seres humanos interactuaron por primera vez con la caña hueca.

A lo largo de todo el proceso de recolección de datos, suele desasosegarnos a cada paso la inquietud por terminar y entregar de inmediato los resultados de nuestra investigación de tal modo que, cuando se llega a la etapa de la ordenación e interpretación, se siente un verdadero placer porque nos sentimos liberados de una larga tarea en extremo empírica, aunque, en verdad, esta nueva labor tiene sus propias dificultades y requiere nuestro esfuerzo. (Zubizarreta, 1991, p.74).
La recolección nos habrá proporcionado un determinado número de datos que no solo comprueba, sino que matiza, enriquece y hasta transforma nuestra posición acerca de la función de la caña hueca como fiel testigo de la historia y su estrecha relación con la actividad del tacneño de siempre.

\section{LAS CAÑAS ENTACNA}

Tacna es una tierra privilegiada con este recurso, pues por sus valles se extienden grandes cantidades de dicho recurso natural, entre algunos de ellos están la zona de Ilabaya, Locumba, Ite, Sama, Pocollay, Calana, Calientes, etc.

El clima del departamento de Tacna no es uniforme, debido a sus diferentes regiones naturales, dos terceras partes de su territorio corresponde a la faja de costa y la tercera parte restante se halla situada en las alturas de la cordillera. La temperatura promedio en diez años de observaciones entre 1990 y 1999 es de $16.06^{\circ}$ C. (INEI, 2000, p.21).

Antiguamente, la caña hueca (recurso forestal no maderable) era muy utilizada en Tacna, generando una identidad en los pobladores a través de sus costumbres, creencias y tradición.

Por ejemplo, esto se refleja en el siguiente cuadro que considera a la caña hueca de importancia económica en el departamento de Tacna en este siglo.

Tabla 1

Productos de caña elaborados en Tacna

\begin{tabular}{lll}
\hline Nombre común & \multicolumn{1}{c}{ Usos/ productos } & \multicolumn{1}{c}{ Ubicación } \\
\hline & & Locumba, llabaya, Inclán \\
Caña hueca & esteras, canastas, viviendas & Sama, Locumba, Curibaya \\
Carrizo & esteras & Sama, Locumba \\
\hline
\end{tabular}

Fuente: INRENA, ATCFFS TACNA. 


\section{DESCRIPCIÓN ALEGÓRICA DE LAS CAÑAS DE TACNA}

Tacna, ciudad de San Pedro de Tacna, tiene una serie de microclimas que le dan esa mistura de oportunidades para ser atractiva ante los ojos de su madre patria, el Perú. En ella habitamos quienes amamos las chacras viejas que sobrevivían con llegadas de acequias que inundaban aquellos espacios verdes de este valle tan preciado.

Cuando las gotas de lluvia de los meses de junio y julio caían sobre la tierra de chacra de los callejones, se desprendía el peculiar olor de Tacna; cuando el poblador se posaba bajo los brazos de las frondosas vilcas, aparecían los espléndidos cuculíes ojicelestes rodeados por libélulas y avispas multicolores que le comunicaban el quehacer de esos campos y lo mismo hacían los frutos como los higos negros y las granadas rojas (ambos rajados), las dulces peritas, membrillos agridulces y uvas vigorosas a lo largo de todos sus callejones bordeados de hermosos cañaverales verdes que imponentes delimitaban las chacras de cada propietario.

Cada chacarero conversaba a momentos con el vecino utilizando como interfaz los cañaverales o varias manchas de caña reunidas como linderos entre sus áreas de cultivo

\section{IMPORTANCIA DEL RECURSO CAÑA HUECA}

La caña hueca por estar arraigada desde hace muchos años en territorio tacneño ha pasado a ser parte del entorno del poblador. La artesanía que se elaboraba tradicionalmente era para el uso personal y familiar, mas no presentaba un fin comercial, preservándose así el patrimonio local.

En zonas como Ilabaya, Locumba y Sama, las cañas cumplen la función de defensa ribereña para evitar el desborde del agua de los ríos e inunden los cultivos de nuestros campesinos.
Las casas con techo mojinete, la forma de pirámide trunca que tanto nos enorgullece, fueron construidas con caña hueca para darle las condiciones de vida que tenía el poblador de la época, fresca en verano y cálida en invierno. "Se empleaban en los tijerales de los techos de mojinete, para sostener las cañas unidas por tirillas de cuero fresco sin curtir y con una capa de barro encima, se hacían descansar en las paredes de adobe de las viviendas" (Pérez, 2014, p. 53).

El grupo de manchas de cañas se denominan cañaverales y nos recuerdan a los callejones de antaño que guardaban muchas riñas, amoríos y sucesos de la época, y que hoy van desapareciendo por motivos de la urbanización. Desde tiempos antiguos en la ocupación chilena los cañaverales bordeaban los caminos de aquellos carruajes del país vecino en nuestro país.

Hoy con el flujo de turistas que vienen a Tacna se emplea de manera comercial como productos de souvenir que reflejan identidad tacneña para el mundo entero.

\section{USOS TRADICIONALES DE LA CAÑA HUECA}

Con respecto a otro de los usos que se le daba a este recurso están los juegos infantiles, el uso casero en utensilios, la cestería, instrumentos musicales, viviendas y objetos alegóricos como las antorchas luminosas, entre otros. Todos los productos que a continuación se mostrarán, particularmente, los viví y pude apreciar su resistencia y utilidad para el ser humano.

\section{Cestos}

Canastas elaboradas en base a caña hueca y/o carrizo. Otro tipo de cestos como porta botellas y cestos para almacenar alimentos solían usarse en la época. 


\section{Figura 3}

Canastas de Cañas

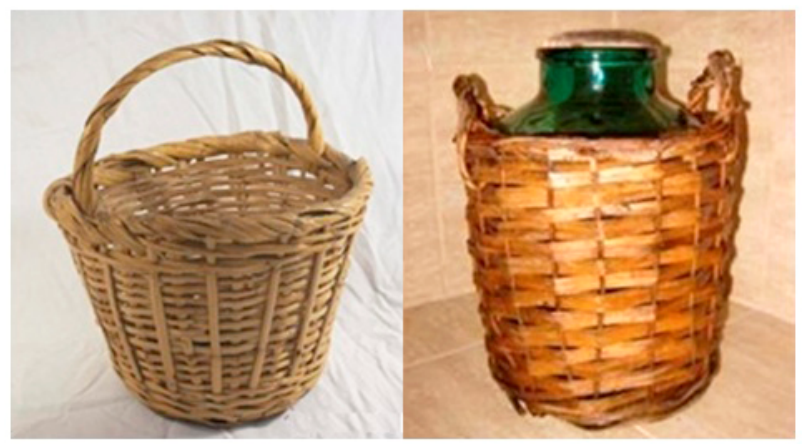

Fuente: Fotografía propia.

\section{Esteras}

Esteras que los pobladores de los valles tacneños elaboraban con fines de vivienda provisional y otros, los materiales a usar fueron el carrizo y/o de caña hueca.

\section{Figura 4}

Esteras de caña hueca

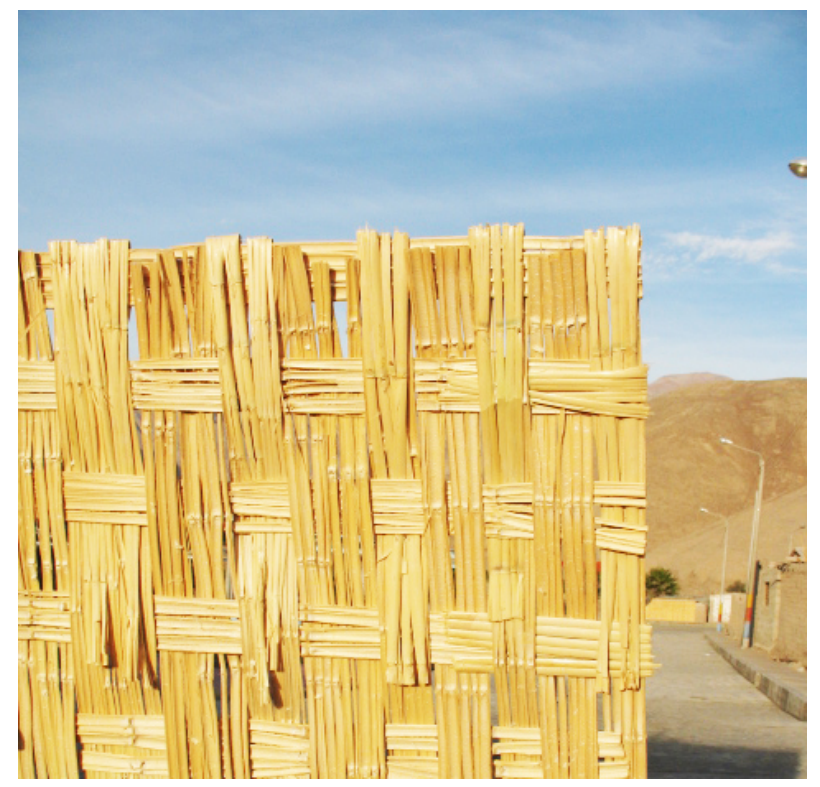

Fuente: Fotografía propia.

\section{Conejeras}

Los pobladores utilizan la caña hueca como separadores de corrales de cuyes y conejos.

\section{Figura 5}

Conejeras con caña

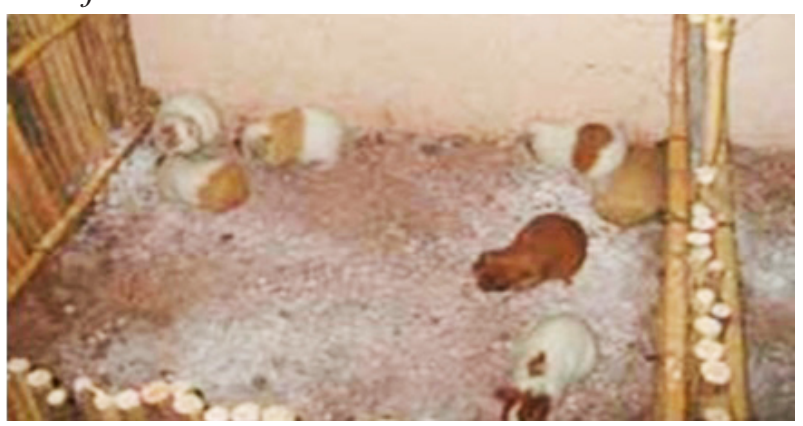

Fuente: Fotografía propia.

\section{Techos de mojinete}

Los pobladores utilizaban la caña hueca en la construcción de los techos por su propiedad de conservación del calor.

\section{Figura 6}

Casas de techos de mojinete

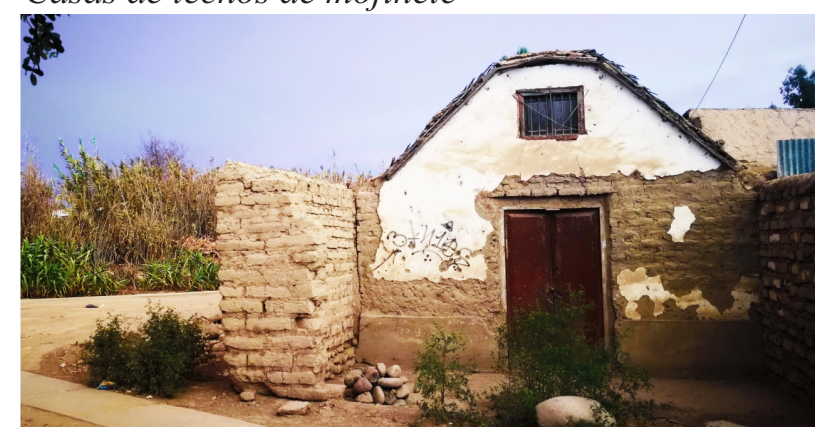

Fuente: Tacna Fascinante (2019).

\section{Jaulas pajareras}

Jaulas para pájaros, hechas de caña hueca cruzadas entre ellas.

\section{Figura 7}

Jaulas de caña

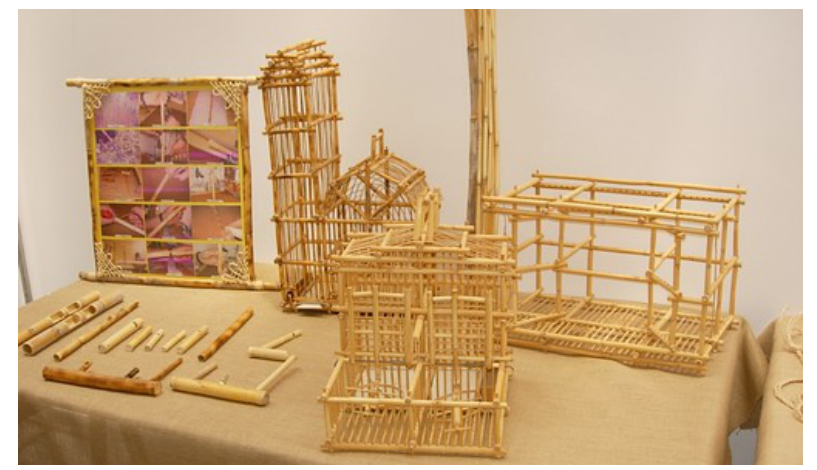

Fuente: Coros y Danzas de Ingenio (2011). 


\section{Soporte de arreglos florales}

Se elaboran parantes de tallos de caña hueca verde para arreglos florales.

\section{Figura 8}

Soporte de Arreglos florales

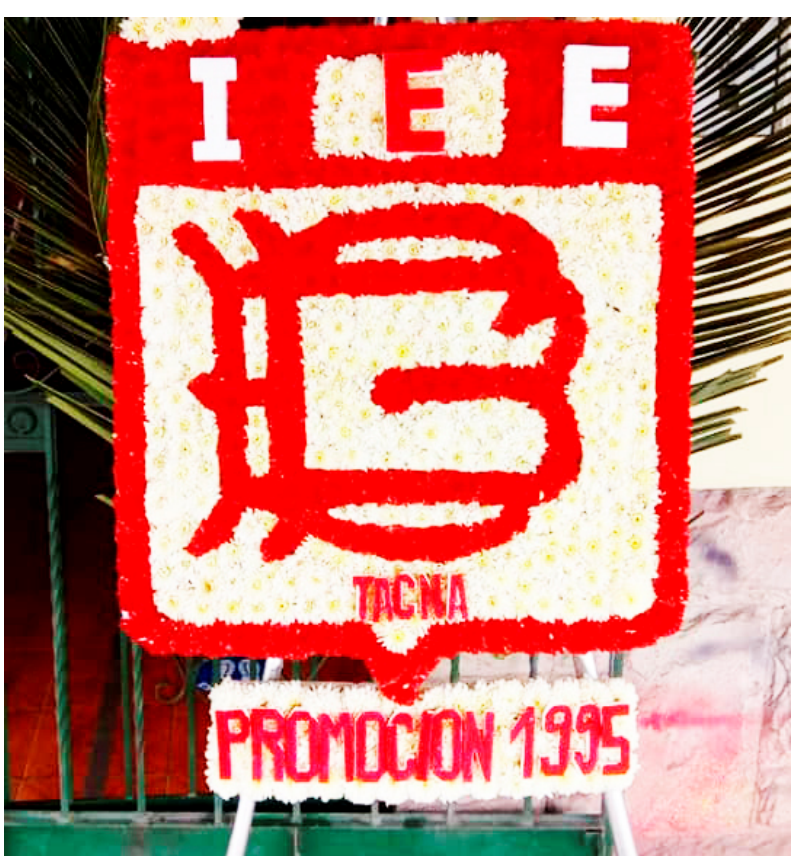

Fuente: Fotografía propia.

\section{Antorchas}

Castillo alegórico elaborado de varios tallos de caña hueca seca. Se utiliza este tipo de trabajos en fechas festivas.

\section{Figura 9}

Antorchas de caña para desfiles

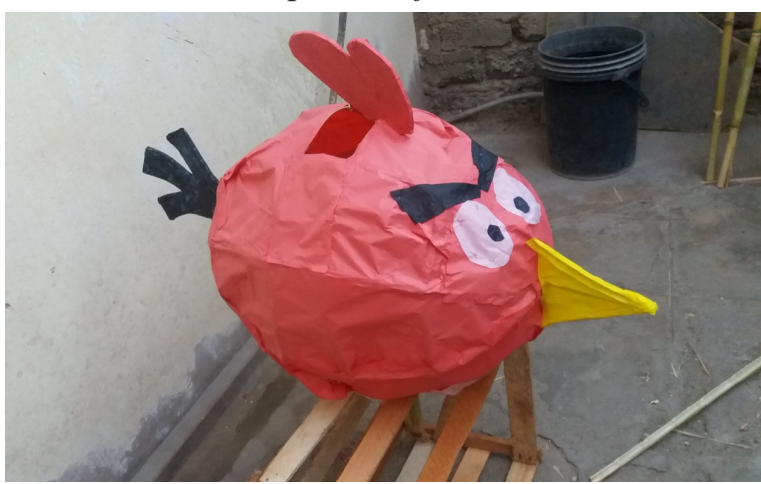

Fuente: Fotografía propia.

\section{Anticucheras}

Palitos elaborados de caña hueca para atravesar la carne de las parrillas.

Figura 10

Anticucheras de caña

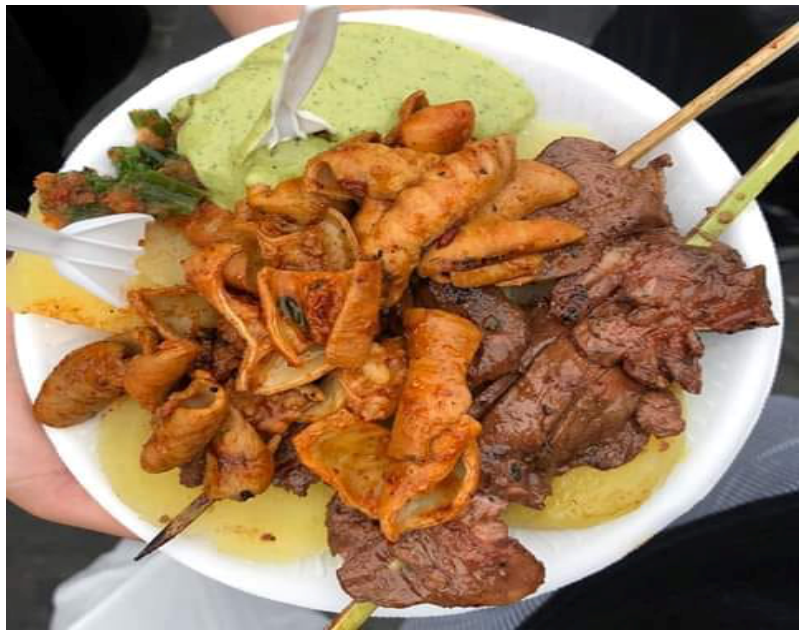

Fuente: Fotografía propia.

\section{Arcos y flechas}

Flechas para jugar al tiro al blanco en los árboles, están elaboradas de caña hueca con pita o pabilo.

\section{Figura 11}

Arco y flecha de caña

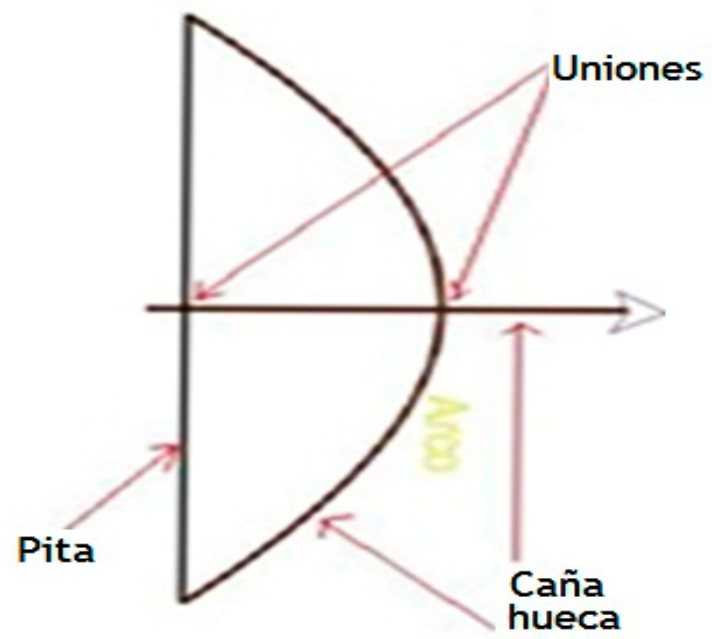

Fuente: Elaboración propia. 


\section{Cometas}

Cometa de papel o plástico con estructura de caña hueca seca para evitar el peso al levantar el vuelo.

\section{Figura 12}

Cometa de caña

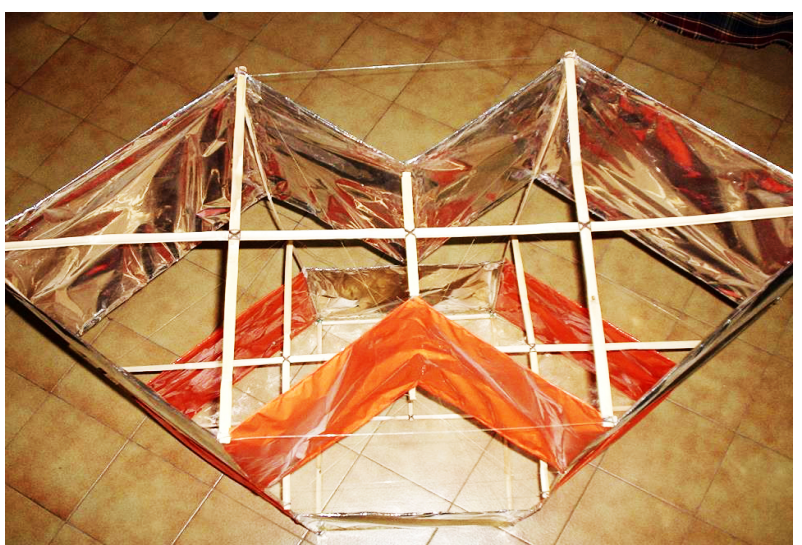

Fuente: Los Planitos de LUPÍN (2017).

\section{Barquitos de hoja de caña}

Pequeños barcos elaborados de la hoja caulinar verde de la caña hueca y que se echaban en las acequias para que naveguen.

\section{Figura 13}

Barquito de caña

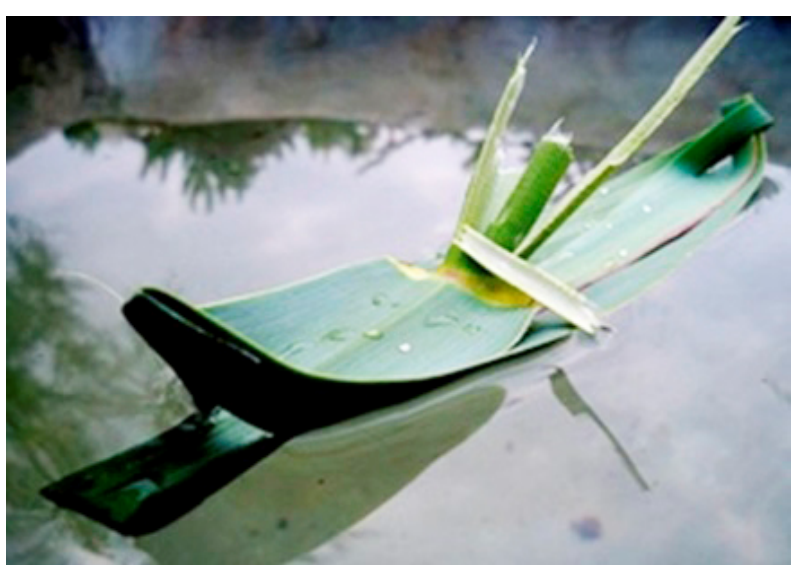

Fuente: Fotografía propia.

\section{Pito caza arañas}

Pito elaborado de la parte más joven y verde de la caña hueca, que emite pitidos que simulan el sonido de una mosca en una telaraña, y que al sonar en la boca de las madrigueras de las arañas se lograba capturar los arácnidos.

\section{Figura 14}

Pito para cazar arañas

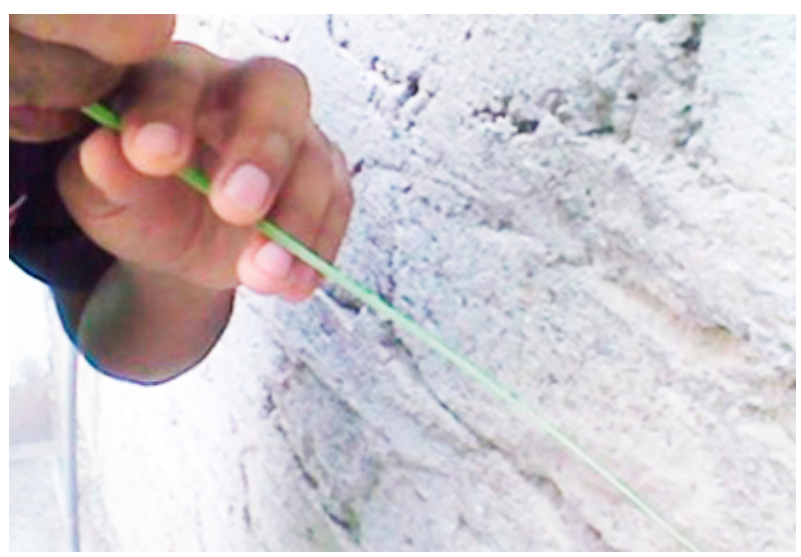

Fuente: Fotografía propia.

\section{Curita de caña}

Pequeña telita que se encuentra encerrada dentro del culmo (tallo) de la caña hueca, casi al nivel del nudo del culmo y que sirve para curar las heridas sobre la piel.

Figura 15

Curitas de caña

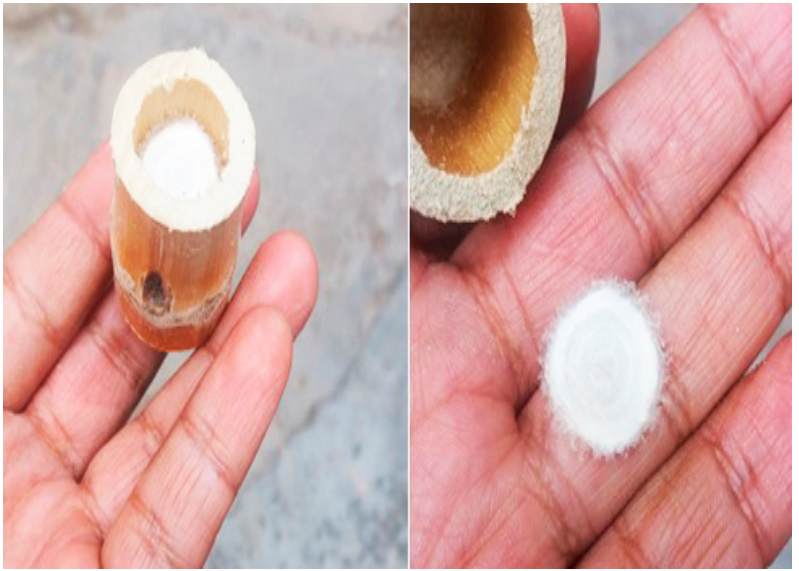

Fuente: Fotografía propia.

\section{Instrumentos de vientos}

Quenas y zampoñas elaboradas de caña hueca y/o carrizo. 


\section{Figura 16}

Instrumentos musicales de caña

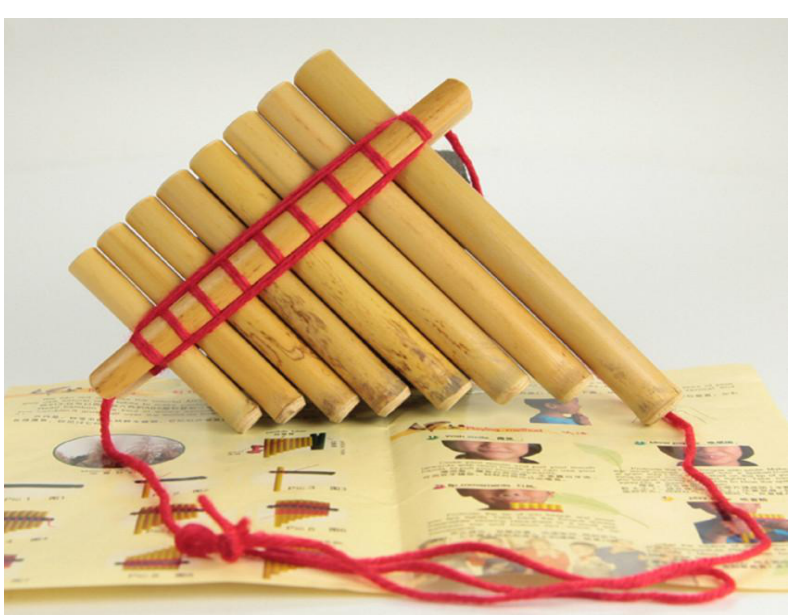

Fuente: Instrumento Musical Paternity Aids Xiao (2004).

La caña hueca tiene más usos de los que conocemos, por ejemplo, en la medicina, artesanía, alegoría, etc. $\mathrm{Y}$ a pesar de ser considerada una de las 100 especies más invasivas de los suelos en Tacna siempre quedará guardada su presencia en la historia.

\section{LA CAÑA EN LA PALABRA DE SUS AMANTES TACNEÑOS}

Es grato recordar como los viejos tacneños de las chacras de la zona del barrio Miraflores (1982), vecinos como la Sra. Martina Siles y el Sr. Lucho Ramos (QEPD y QDDG), entre otros, contaban a los jóvenes de esa época como los carruajes chilenos en época de cautiverio circulaban por esos caminos y callejones. Era como un logro el poder observar esos puentes de piedras de cantería dispuestas para encaminar la ruta de la chilenización lúgubre.

Se puede destacar que dichas cañas tuvieron presencia siempre en la vida del poblador de Tacna. Alguna vez, el intelectual Jose Giglio Varas (QEPD y QDDG) comentaba que el poblador de antaño de las zonas del valle viejo recibía a sus visitantes con zapallito de carga y en un pequeño cesto de caña y/o carrizo la canchita como entrada, para amenizar la conversación que allí se preparaba.
Tacna es cuna de poetas que alaban las bondades del tacneño y su naturaleza, uno de ellos es el profesor Luis Alberto Calderón Albarracín con su poema titulado "La casa propia" (Calderón, 2003, p.49). Este poema se encuentra en el libro "Paisajes de los espejos, espectros y otros secretos" y hace mención a un producto derivado de nuestra caña hueca que se utilizaba por los pobladores de nuestros valles para sus viviendas, las esteras... Y que a su letra versa:

\section{Una estera \\ un terreno para la casa propia \\ Anhelado anhelo \\ de los pobres \\ que se siembra \\ como un árbol \\ sobre la arena.}

Asimismo, la dramaturga, declamadora y poetiza Raida Callalle Tello también hace mención de la caña en su poema titulado "Cambuchito" y resalta su uso como material didáctico para elaborar sus marionetas y que a su letra versa:

$$
\begin{gathered}
\text { Con una caña } \\
\text { Yun pedazo de papel } \\
\text { Nació cambuchito } \\
\text { Para mi bien } \\
\text { Con él, } \\
\text { Vuelo y vuelo } \\
\text { de aquí por allá } \\
\text { por toda la tierra } \\
\text { buscando en el cielo } \\
\text { lo que el hombre no pudo encontrar } \\
\text { ¿Por qué mueren los niños sin crecer? } \\
\text { ¿Por qué los grandes nos hacen llorar, } \\
\text { Si sólo alegrías sabemos dar? } \\
\text { Vamos, cambuchito, } \\
\text { Al frente está el sol, } \\
\text { ¡Cuidado!, te vas a quemar } \\
\text { ¡Todavía no! } \\
\text { Porque hay rumor de respuesta } \\
\text { Que mis oídos quieren escuchar. }
\end{gathered}
$$

También se reconoce el valioso callejón de los recuerdos que han calado en el corazón tacneño, en un fragmento de palabras de la profesora 
Eleanor Zelada de Díaz en la sección "Mis callejones tacneños" (Albarracín y Mello, 2019, p.130). Y que se encuentra en el libro de culinaria tacneña titulado "Al pie del Fogón" y que a su letra dice:

$$
\begin{gathered}
\text { A poco solo quedará recordar } \\
\text { a la Tacna campesina } \\
\text { de sus viejos callejones, } \\
\text { de los pagos ancestrales, } \\
\text { de mis molles, de las vilcas, } \\
\text { de sus coquetas buganvillas, } \\
\text { de las fresias amicales, } \\
\text { de los lirios, de los juncos, } \\
\text { de polvorientos cañaverales. }
\end{gathered}
$$

Como no recordar las sabias palabras del recopilador y declamador ilabayeño, tacneño de corazón y de razón, profesor Santiago Camacho Rosado quien en su palabra nos comenta su experiencia con nuestra tan amada caña:

"Amante de Tacna por su riqueza cultural, histórica y tradicional. Y de Ilabaya, tierra qué me vio nacer, como no la voy a querer. De caña fue mi casa con techo de mojinete, de caña fue mi caballito, juguete preferido, de caña fueron las canastillas donde recogía las ricas brevas, uvas, pacaes, guayabas, frescos choclos y demás productos que producía y sigue produciendo esta linda y fértil tierra."

Quien se refiere a los objetos utilizados y elaborados de caña hueca durante la época de su niñez y que formó parte de su vida.

La música no es ajena; por ello, en la canción "Reliquias tacneñas" de autoría del profesor Marco Aurelio Tapia Alarcón y cantado por la Sra. Sonia Vildoso hacen mención enérgica a las cañas en su frase:

"Y los cañaverales como dardos gigantes, controlan vigilantes el andar de los años, resistiendo soberbios el avance incansable del constante urbanismo que acecha sin cesar".
Estos son unos ejemplos de amor por nuestros mudos testigos del cambio de Tacna antigua a Tacna contemporánea.

\section{LA CAÑA COMO ARTESANÍA DE IDENTIDAD}

Ante todo queremos asentar que la cultura es un apretado tejido de relaciones, y que las artesanías abren una ventana para comprender y visualizar la conexión integral entre los elementos naturales, sociales y simbólicos del grupo social en cuestión. Esta es la primera premisa para dimensionar el origen y significado de las artesanías. El hombre siempre está en el primer plano, y es el esfuerzo que tiene que invertir cada grupo para la obtención de sus satisfactores primarios el que determina su capacidad organizativa. Históricamente, la mujer ha sido alfarera y la tejedora, y el hombre el tallador y herrero; la gradual especialización de sus miembros a través de una división del trabajo ha contribuido a la multiplicación de las expresiones artísticas y estéticas de los objetos que se elaboran para fines domésticos, rituales o ceremoniales. Su forma de producción, su uso o función, su decoración y su simbolismo deben verse como expresiones concretas, es decir, materiales de la cultura. (Turok, 1988, pp. 19-20).

En Tacna no se ha apreciado artesanía que la identifique profundamente con sus recursos naturales; sin embargo, si consideramos a la caña como parte inherente de nuestro modo de vida de antaño podríamos decir que siempre la tuvimos como identidad al compartir gratos momentos con este recurso.

\section{LA CAÑA COMO POTENCIAL FUENTE DE INGRESOS}

La vida del hombre siempre ha estado ligada a la realización de actividades que le permitieran obtener alimentos, confeccionar sus vestidos, 
construir su vivienda, alcanzar el mayor confort material, o elevar su calidad de vida; actividades que involucran el concepto de trabajo. Se ha considerado el trabajo como el esfuerzo mental o corporal ejecutado por el hombre, tal que le permita su realización plena como persona humana; lo que es inherente a su naturaleza, dignidad, progreso, bienestar y confort.

El trabajo, al mismo tiempo que es un deber, es también un derecho. Es un deber en cuanto es la obligación que tiene todo hombre de trabajar para satisfacer su propio sustento, necesidades familiares y de la propia comunidad. Es un derecho en tanto es obligación de la sociedad promover y promocionar fuentes de trabajo al ser humano admitiendo participar en los esfuerzos orientados hacia el logro y bienestar de la comunidad en general. El trabajo es fuente primigenia de la producción de riqueza; de bienes y servicios. Con el trabajo es posible el crecimiento y desarrollo económico de los pueblos.
Precisando aún más el concepto, consideramos que el trabajo es la energía humana ejercida sobre la naturaleza, en sus diversas formas naturales, transformaciones artificiales y tecnológicas que retorna al hombre en nuevas formas productivas, creativas, intelectuales $\mathrm{o}$ materiales para asegurar su existencia y el bienestar material y el desarrollo socioeconómico personal, local, regional y nacional (Reyes, 2003,pp.11-12).

A través de los años, la caña ha servido para la producción de esteras por parte de los pobladores del departamento de Tacna, y su posterior comercialización mediante atados.

En el resto del país de igual manera se ha aprovechado este recurso; sin embargo, presenta futuros y prometedores usos no solo para Tacna, sino para el país y porque no para el mundo, pues podemos replicar este modelo en otros países que gocen de este recurso en sus campos.

Tabla 2

Producción de esteras en los valles de Tacna

\begin{tabular}{lclc}
\hline \multirow{2}{*}{ Producto } & Unidad de medida & Año 2000 & Año 2001 \\
\hline Esteras de caña hueca & unidad & 2912 & 3065 \\
Esteras de carrizo & unidad & 2217 & 1570 \\
Caña hueca & unidad & 90 & 442 \\
& & & \\
\hline
\end{tabular}

Nota: La información presentada corresponde solo a la producción controlada.

Fuente: INRENA, ATCFFS TACNA.

Con las nuevas tendencias en las Micro y Pequeñas Empresas (Mypes) se puede integrar el trabajo con la caña hueca para generar fuentes de empleo en estos nuevos tiempos.

\section{A S C A Ñ A S E N L A É P O C A REPÚBLICANA}

Como se mencionó, la caña hueca se ha establecido en América durante el siglo XIX aproximadamente. Probablemente a finales de ese siglo, llegó a nuestras costas hasta nuestros días como país en el período republicano. En la historia no se le menciona mucho a las cañas, pero sí se sabía que existían los callejones ensimismados con los pagos en lo que hoy llamamos Tacna.

Como un cordón verde circundaban la ciudad los pagos y ayllus ancestrales. Los pagos Humo, Olanique, Aymara, Aica, Tonchaca, Silpay, Collana, Capanique eran 
gobernados por sus comisarios o principales. En 1879, la mayoría absoluta de los pequeños propietarios de las chacras y chacarillas de estos pagos, eran originarios o indígenas tacneños. Representaban a 303 contribuyentes en el distrito del cercado y a una población aproximada de 3000 habitantes (Choque, 2016, p.119).

Las "chacarillas" o extensiones mínimas de tierras de cultivo, similares a las actuales parcelas y cuyos límites no sobrepasaban la hectárea son los de predominio absoluto. Las "chacras" son propiedades que bordean los límites que tipifican la propiedad minifundista. Por ello, Jorge Basadre decía: "La división agrícola del valle es otro sello de inconfundible peruanidad". Las haciendas de regular extensión apenas sumaban la decena, en 1880 (Choque, 2016, pp.143-144).

El 25 de junio de 1875, se creó el departamento de Tacna al segregarle Moquegua, que quedó convertida en "provincia litoral". Después de la Guerra del Pacífico, Tacna quedó cautiva hasta que fue devuelta a la patria, de acuerdo con el tratado del 3 de Junio de 1929, el 28 de agosto de ese mismo año (Grupo editorial PEISA, 2004,p.18).

La Tacna de hace cien años era radicalmente diversa, pues aún no había desarrollado ni su activo comercio, ni la minería de Toquepala; además, dependía de una agricultura que, a su vez, vivía limitada por la escasez de agua. Se ha dicho mil veces que este elemento es el gran condicionante para el desarrollo de la agricultura (es sintomático que el Caplina, que pasa cerca de la capital del departamento, sea un río que se seca antes de llegar al mar).

La agricultura de Tacna depende enteramente de las irrigaciones que puedan desarrollarse (peor aún mantenerse), ya que incluso la laguna de Aricota (ubicada en el distrito de Curibaya), su principal fuente de abastecimiento de agua, amenaza secarse; por lo que su afianzamiento es una tarea prioritaria y ello puede notarse en el hecho de que el $99.41 \%$ de sus tierras agrícolas están bajo riego, el porcentaje más alto del Perú.

La estructura de la propiedad de la tierra se mantiene como antes. Tacna nunca fue zona de grandes haciendas, pues estas tierras están repartidas en casi 9000 unidades agrícolas.

La diversidad de las costas tacneñas se estrella contra la aridez y hostilidad de uno de los desiertos más extensos del mundo. Esta tierra de dunas sin fin, cubierta durante gran parte del año por las densas camanchacas, es en realidad el extremo septentrional del desierto de Atacama, uno de los lugares más áridos del mundo, donde incluso las bacterias no logran sobrevivir.

A pesar de encontrarse inmersa en el límite septentrional del desierto de Atacama, la ciudad se refugia en el corazón de un fértil valle agrícola. Muestra de ello son sus excelentes viñedos, cuna de un pisco de polendas, y olivares considerados entre los más productivos del Perú.

Los valles de Tacna fueron el escenario de diversos esfuerzos de desarrollo agrícola propios del lugar entre los años 1500 a.C. y 200 d.C. Los estratos más antiguos de Locumba, Sama y Caplina muestran rastros de aldeas típicas del período "formativo temprano", semejantes a aquellos de los sitios de Lluta y Azapa (hoy en Arica, Chile), que sin duda fueron parte de un mismo fenómeno cultural (Grupo editorial PEISA, 2004).

Arica comparte con Tacna hasta ahora, recursos como la caña hueca.

Entre 1850 y 1879 , el departamento de Tacna tuvo un importante desarrollo comercial, no obstante los fuertes terremotos sufridos en 1863 y 1868 . Se propagó ampliamente en la arquitectura popular el uso de los techos redondeados, 
de estilo "mojinete", que vino a ser un rasgo característico de las viviendas tacneñas, moqueguanas y tarapaqueñas. En agosto de 1868, un grupo de aventureros buscó en la localidad de Locumba el tesoro que, según antiguas historias, había ordenado enterrar allí un general inca luego de la muerte de Atahualpa. La leyenda decía: $\mathrm{Al}$ desenterrar encontrarás una llama, luego una canasta con un lorito, después estarán las cargas de oro (Grupo editorial PEISA, 2004, pp.46-47).

Aquí hacen mención de una canasta de fibra vegetal aparentemente.

\section{Figura 17}

Tacna y su herencia colonial, los techos de mojinete

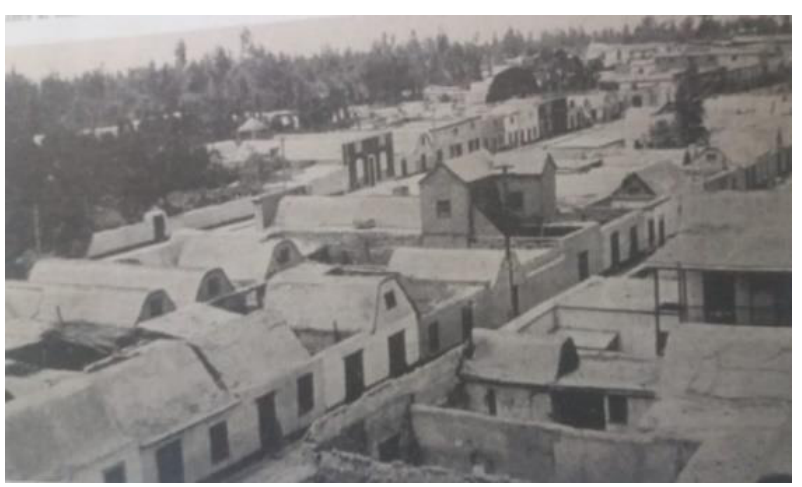

Fuente: Grupo editorial PEISA - 2004

\section{LA AGRICULTURA COSTEÑA EN EL PERÚ}

Las tierras del país, al igual que su agricultura han sufrido cambios a lo largo de la historia, en el siguiente texto se menciona:

A la larga las cosechas de ex-portación terminaron primando. Primero hasta fines del siglo XVI, el vino. Más tarde la caña de azúcar, esta última complementada por el maíz destinado al engorde de cerdos para el mercado de la capital. La estructura de relaciones originada de este modo, parece haber sido bastante estable durante la Colonia y en la primera mitad del siglo XIX (Matos, 1976, p.20).
Se refiere a que la caña hueca durante la primera mitad del siglo XIX habría convivido con esos recursos en el Perú.

Por otro lado, José Carlos Mariátegui describe dentro de sus siete ensayos de la interpretación de la realidad peruana lo siguiente con respecto a la agricultura y su subordinación al extranjero:

El grado de desarrollo alcanzado por la industrialización de la agricultura, bajo un régimen y una técnica capitalista, en los valles de la costa, tiene su principal factor en el interesamiento del capital británico y norteamericano en la producción peruana de azúcar y algodón. Las mejoras de las tierras de los valles de la costa están sembradas de algodón y caña, no precisamente porque sean apropiadas sólo a estos cultivos, sino porque únicamente ellos importan, en la actualidad, a los comerciantes ingleses y yanquis.

Los frutos alimenticios destinados al mercado interno, están generalmente en manos de pequeños propietarios y arrendatarios. Sólo en los valles de Lima, por la vecindad de mercados urbanos de importancia, existen fundos extensos dedicados por sus propietarios a la producción de frutos alimenticios. En las haciendas algodoneras y azucareras, no se cultiva estos frutos, en muchos casos, ni en la medida necesaria para el abastecimiento de la propia población rural (Mariátegui, 1972, pp. 96-97).

Nótese que para José Carlos Mariátegui, la caña referida es la caña de azúcar cuyo nombre científico es Saccharum officinarum y es cuando nuestros territorios eran productores de azúcar. También menciona que han sido obligados a albergar esos recursos por el mero interés comercial sin respetar lo que la tierra dignamente ofrece al poblador rural de las demás zonas del país.

Las frutas que consumimos los tacneños hasta el año de 1990 libremente no eran bien vistas para 
la economía, y mucho menos los cañaverales de caña hueca. Sin temor a equivocaciones, podría ser que muchas manchas de caña de azúcar se hayan desplazado en las riveras de las acequias a la caña hueca.

\section{LA CAÑA HUECA ES MUDO TESTIGO DE LA CRUELDAD Y DE APASIONAMIENTOS DURANTE ELCAUTIVERIO}

Razón no les faltaría para argumentar ello, pues las cañas están muy arraigadas en este extremo sur del país y cuando antes se las veían reinantes en los callejones amplios, eran fieles testigos de acontecimientos suscitados incluso en los tiempos del cautiverio, amores de callejón, escondites de algún bribón, o quizá hasta algún crimen callado por el tiempo, pero las cañas manchadas también de sangre no hablan y solo se reproducen, haciendo aparecer más cañas nuevas, cuando las viejas se secan, gracias a sus raíces.

\section{Entendiéndose por raíz como:}

El eje del cormo que crece en dirección inversa a la del tallo y, por lo tanto, posee generalmente geotropismo positivo. Introducida en la tierra, en el agua o en otros medios, extrae de ellos las sustancias nutritivas que necesita el vegetal para su desarrollo y existencia. (Jabal, 1981, pp. 6364).

Pero en esencia, esas cañas heredarían los "saberes y testimonios" de las cañas viejas a través de sus rizomas (raíces), que son casi perennes. Algunas de ellas siguen hasta hoy en pequeños tramos de callejones escondidos en la penumbra de esta actual Tacna. Esto a través de su savia bruta que sube desde los rizomas hasta las hojas de la caña y luego de la fotosíntesis se transforma en savia elaborada y que se reparte a todo el resto de la planta, incluso hasta sus rizomas.
Si planteamos metafóricamente este punto cognitivo de la planta de la misma manera que lo hacen (en referencia a los monumentos históricos de Tacna) como el arco de los héroes, la Fontana o la catedral, diríase que tendría más sentido decir que a través de la savia elaborada transportaban todos los conocimientos y experiencia que las cañas en la intemperie capturan para ser almacenados en el rizoma. El cual conserva bajo tierra toda esa información para ser repartida a la nueva generación de cañas de los cañaverales de Tacna, información vivida desde el cautiverio hasta nuestros días. "Aunque la caña gigante puede producir semillas en algunas condiciones, no hay evidencia de que las semillas sean viables. En consecuencia, la reproducción es estrictamente a partir de piezas de tallo y rizoma" (Odero y Ferrell, 2018, p. 2).

No sería ilógico decir que dentro de los culmos de caña hueca con propiedades acústicas se podía haber grabado cada sonido vivido durante aquellos tiempos de tortura tacneña; y por ello, no sería ilógico pensar que la caña es desde ese punto de vista, parte de la historia de Tacna.

\section{Figura 18}

Savia elaborada de una planta (Tejido vegetal)

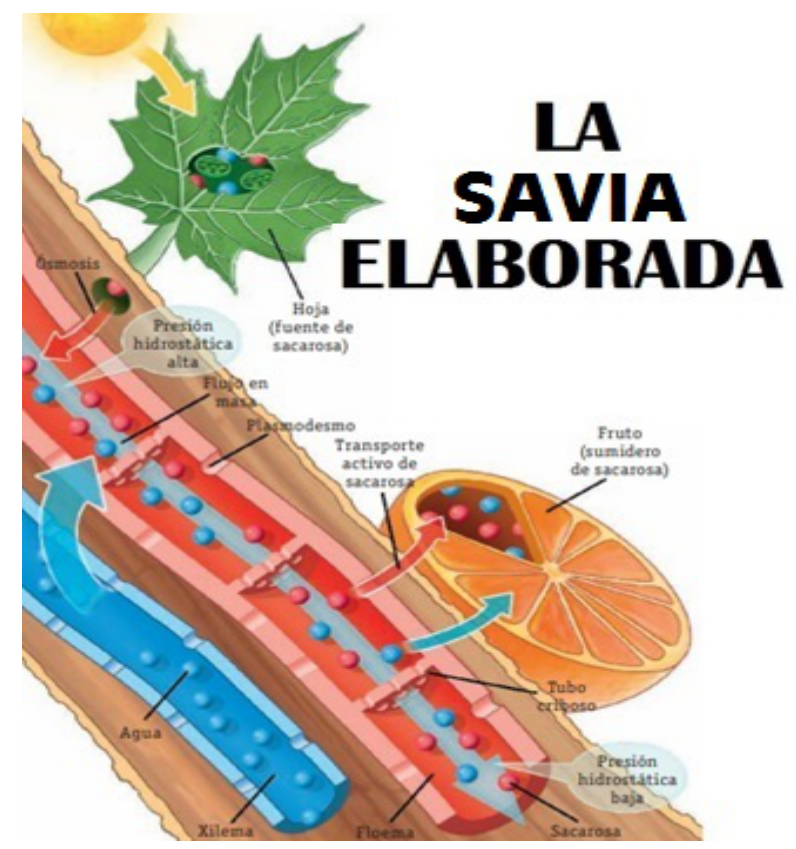

Fuente: Margulis \& Sagan. 
Figura 19

Savia elaborada de una planta (Funcionamiento)

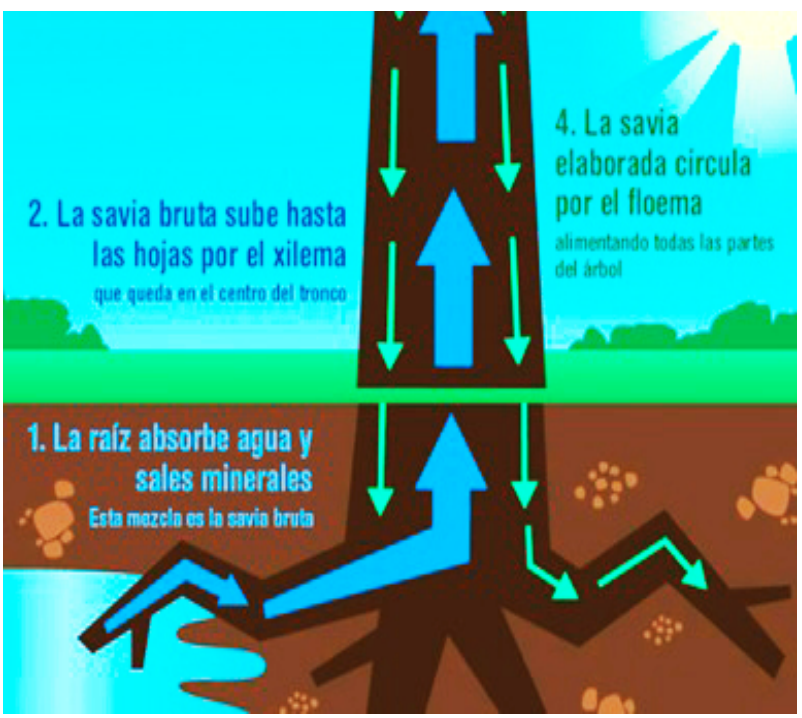

Fuente: Aire Libre, 2016

Se trae esto a acotación por el hecho de ser una planta muy resistente y que muchos tratan de erradicarla por varios métodos: incendios, cortes y hasta herbicidas que las cañas repelen; "el arrancado de la caña y el rizoma con una máquina retroexcavadora es una técnica muy efectiva que permite la retirada completa e inmediata de la caña" (Mota, 2014). Pero debe ser de manera eficiente porque la caña no perdona y rebrota al menor rizoma que pueda quedar en el campo pudiendo vivir muchos años.

Los cañaverales de las pocas chacras y callejones que quedan han estado allí desde mucho tiempo atrás, en las riveras de la acequias y con mucha más razón sus rizomas que podrían tener más de 100 años de longevidad, brotando de ella tantas cañas posibles que el antiguo poblador utilizó para satisfacer alguna necesidad como para poder llevar a cabo la construcción de sus casas con techos de mojinete.
Figura 20

Rizoma de la caña hueca

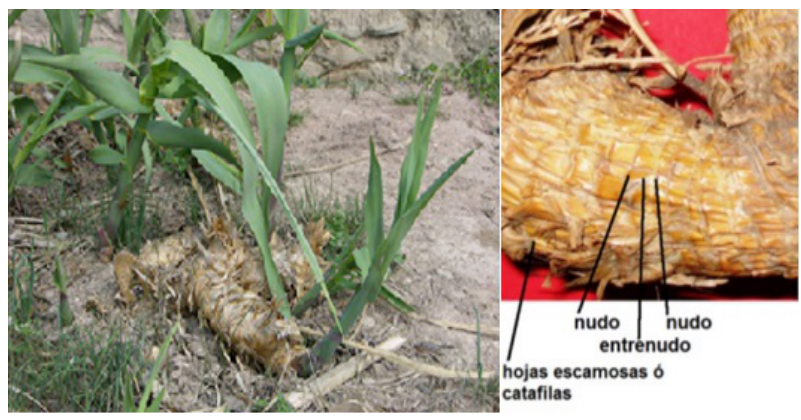

Fuente: Fotografía propia

En plena ocupación chilena (1879-1929), específicamente el año 1903 nació el hijo ilustre de Tacna: Don Jorge Basadre Grohmann, quien a lo largo de su vida emanaba amor profundo por esta tierra del sur peruano. Con justas razones se le llama historiador de la república, porque es quien ha vivido en carne propia toda la barbarie de aquellos tiempos. En una entrevista dada a un periodista local, se le preguntó ¿Qué le hizo historiador? A lo que don Jorge Basadre a sus 70 años responde:

Nací en Tacna durante la época del cautiverio, durante la ocupación chilena. El recuerdo que evoco es el asalto a las imprentas tacneñas "La voz del sur" y "El Tacora" por obreros chilenos que trabajaban en la construcción del ferrocarril Arica- La paz. Pasaron frente a mi casa. Tenía ocho años y vi como apedreaban los balcones de mi casa. Es que se trataba de sofocar la educación y la expresión peruana. (Comisión de admisión de la Universidad Nacional Jorge Basadre Grohmann [UNJBG], 2003, p.33).

Es testimonio de una persona que vivió en Tacna tanto en tiempo y espacio. En ese momento los cañaverales estaban algo lejos de su vista porque 
se encontraba lacerado por todo al mal accionar del chileno hacia el peruano. Sin embargo, no se ensañaron con las tierras ni con nuestros recursos naturales, y por ello las cañas continuaban observando vigilantes las efemérides de esos 50 años.

\section{LAS CAÑAS EN LA ACTUALIDAD Y DESPUÉS DELCAUTIVERIO}

Después del cautiverio, nuestros campos de cultivo sufrían un revés, y las cañas observaban todo ello desde sus rizomas, no parando por ello su producción en las riveras de las acequias. E1 diario La Nación el año 1931 señala:

En sus ediciones del 20 y 21 de febrero de 1931, pone de manifiesto la profunda preocupación social por el alza de los precios de los productos de primera necesidad, además por la escasez de moneda fraccionaria. Después, otros artículos periodísticos describirán la crisis de la agricultura y el comercio, y plantearán como alternativa priorizar la construcción de carreteras y el desarrollo de la agricultura de frutales (Panty, 2018, p. 39).

Mientras en otros espacios como el europeo en 1965 ya gozaban de sus nuevos productos derivados de la caña hueca, nosotros seguíamos con la tradición en sus usos, algo de ello se puede apreciar en el producto de la siguiente figura, donde apreciamos una mesita de caña hueca verde y que el europeo en su afán de buscar alguna utilidad de este maravilloso recurso natural encuentra respuestas.

\section{Figura 21}

Silla de caña hueca

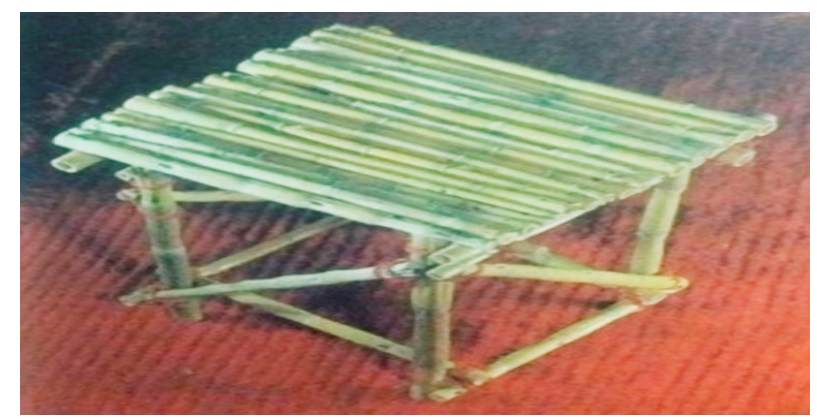

Fuente: Cheridi, Fuentes, Guerrico, Polonio, Molina, Vento, Carreño \& Levi, 1973.
En Europa comentan acerca de estas utilidades como "trabajos realizados a partir de los simples y bellos materiales que la naturaleza nos ofrece" (Cheridi et al., 1973, p.7).

Más adelante la caña hueca se reinventa por parte de su pueblo, desde sus chacras hacia una mejor posición en la vida humana.

Diversas entidades están tomando mayor importancia a este recurso natural que fue parte de la vida del poblador de la región, podemos mencionar algunos usos en la actualidad como el de las esculturas y las piezas de artesanías utilitarias desde 1997.

\section{Figura 22}

Artesaníafina en caña hueca (Portalapiceros)

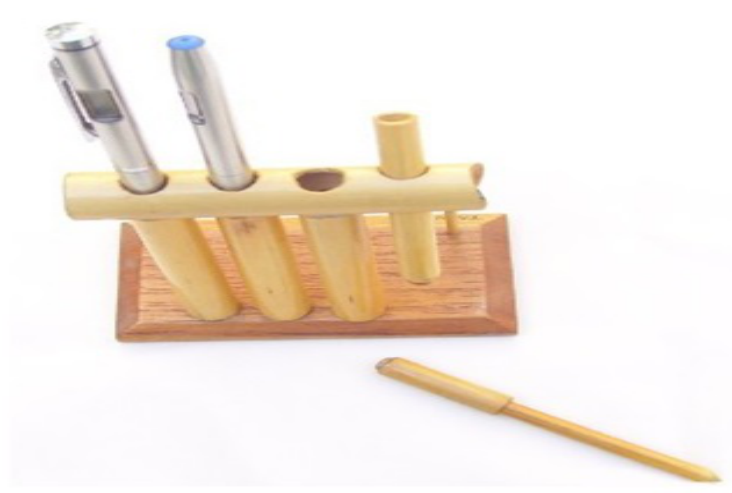

Fuente: Propia

También existe un proyecto que puso en valor este recurso como identificación para un valle rico en cañas, es el caso del proyecto de inversión pública Fortalecimiento de las Capacidades para la Producción de Artesanía en Caña en las Localidades de Mirave, Chulibaya, Poquera y Chejaya, Distrito de Ilabaya Jorge Basadre, Tacna, declarado viable el año 2007 y con código SNIP 70202 se ha ejecutado del año 2009 al 2011 y donde se menciona:

Para la confección de esteras es necesario la extracción de la caña, actualmente esta actividad se hace sin asistencia técnica, cada artesano lo realiza sin tomar en cuenta las consecuencias que pueda acarrear esta operación mal realizada. En visita de campo se ha podido ver que muchas veces los 
artesanos llegan a extraer inclusive la raíz de la planta. (Municipalidad distrital de Ilabaya, 2007, p. 75).

En este proyecto se ha capacitado a más de 100 personas en recuperar los conocimientos ancestrales para la práctica actual en el trenzado de esteras y tejido de canastas hechas de caña hueca y carrizo. Asimismo, se capacitó en nuevos productos derivados de ella, productos de artesanía fina. Luego de ello, más entidades como la Dirección Regional de Comercio Exterior y Turismo (DIRCETUR), Instituciones Educativas (II.EE.) y otros municipios tomaron interés en poder replicar esta iniciativa en favor de revalorar este recurso en Tacna.

\section{Figura 23}

Pobladora del distrito de Ilabaya con sus productos de cañahueca

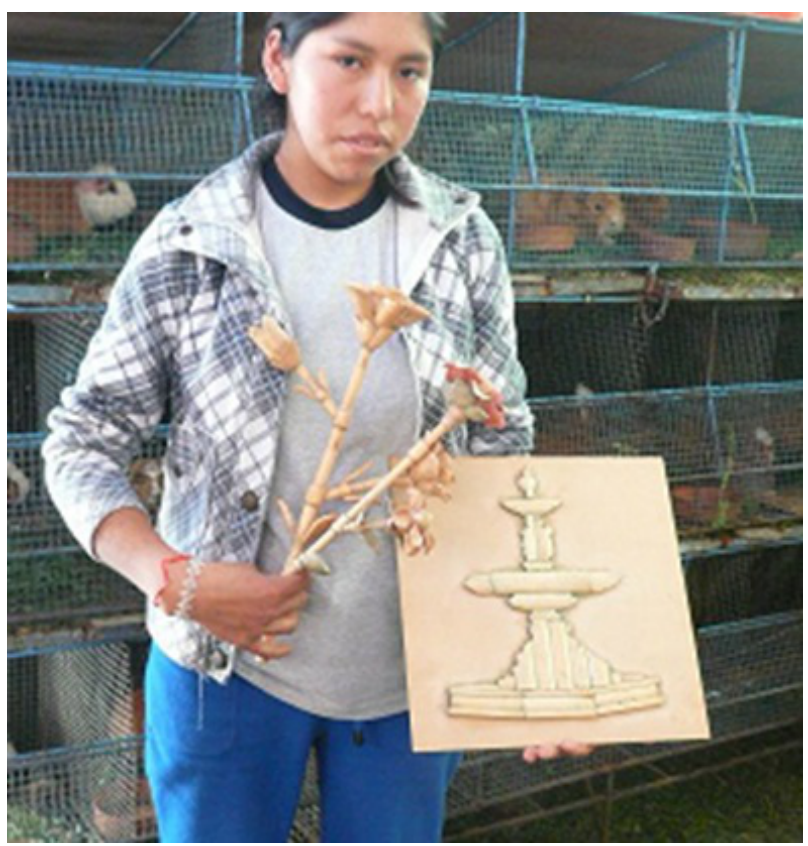

Fuente: Fotografía Propia

Hoy se revalora el uso de este recurso mediante la artesanía fina en caña hueca en la cual los pobladores de Tacna elaboran productos con calidad de exportación y fortaleciendo nuevamente la identidad de antaño.

\section{Figura 24}

Exposición de arte popular contemporáneo en caña hueca de Tacna

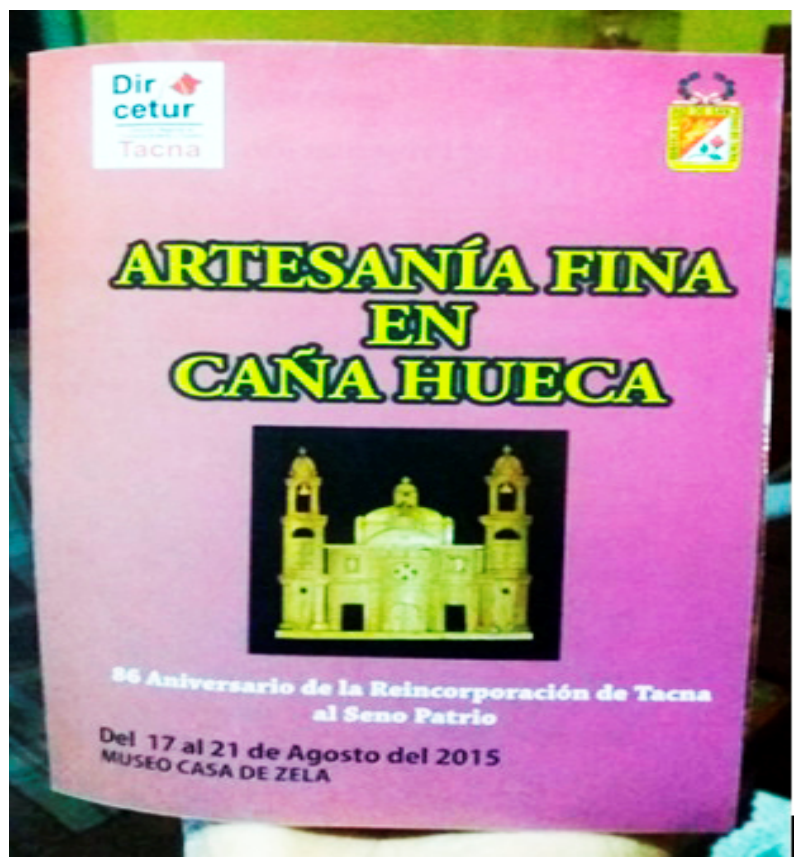

Fuente: DIRCETUR, Tacna - 2015

\section{CONCLUSIONES}

La investigación acerca de la caña hueca, como producto del reino vegetal, es innegable por los muchos usos que se hacía de ella desde antaño. Implícitamente, lo muestran las construcciones de los techos de mojinetes de las casas de la Tacna antigua.

Una gran limitación fue que no se encuentran muchos estudios llevados a cabo sobre la caña hueca en la ciudad de Tacna. Y, al no haber muchos estudios realizados sobre estos hechos, se tuvo que acudir a los cultores del arte, quienes a través de la poesía o canciones dejan vestigios a seguir acerca de la importancia de las cañas en Tacna.

La época del cautiverio no solo afectó al poblador de Tacna y generó un retardo en el reconocimiento de la caña hueca como materia de identidad regional. Ligado a esto fue que no 
hubo libertad de gozar las tierras que pisaban. Campos de cultivo que también sufrieron de 50 años de estar rodeados de decisores ajenos a su libertad desde antes de la república.

En la actualidad, el uso de la caña se ve prometedor y no solo a nivel regional, sino ahora con las nuevas tecnologías trasciende las fronteras nacionales.

\section{REFERENCIAS}

Aire Libre (2016). ¿Cómo circula la savia por el árbol? R e c u p e r a d o d e http://airelibre.cl/como-circula-lasavia-por-los-arboles/.

Albarracín, Y. \& Mello, M. (2019). Al pie del fogón. Tacna, Perú: Fábrica de contenidos.

Bell, G. (1997). Ecology and management of arundo donax, and approaches to riparian habitat restoration in southern California. Plant Invasions. Estudios de Norteamérica y Europa, 103-113.

Calderón, L. (2003). Paisaje de los espejos espectros y otros secretos. Tacna, Perú: ARCOIRIS.

Cheridi, M., Fuentes, J., Guerrico, M., Polonio, J., Molina, P., Vento, J., Carreño, F. \& Levi, L. (1973). El Trébol de Papel. Madrid, España: Santillana.

Choque, E. (2016). Historia de Tacna. Tacna, Perú: Feria Perú Representaciones S.A.C.

Comisión de admisión de la UNJBG. (2003). Homenaje en el centenario de su natalicio 1903-2003. Tacna, Perú: Oficina de admisión de la UNJBG.

Coros y Danzas de Ingenio (2019). Jaulas de c $a \tilde{n} a$. R e c u p e r a d o d e http://www.folkloredeingenio.com/btnetnografia-folklore/104-2016/597-unaexposicion-de-jaulas-elaboradas-concana-recuerda-el-esplendor-que-vivioa-partir-del-xvi-este-articuloartesano.html

Deltoro, V., Jiménez, J. \& Vilán, X. (2012) Bases para el manejo y control de Arundo donax L. (Caña común). Valencia, España: Conselleria d'Infraestructures, Territori i Medi Ambient. Generalitat Valenciana.

Grupo editorial PEISA. (2004). Atlas regional del Perú. Lima, Perú: Ediciones PEISA S.A.C.

Dirección de comercio exterior y turismo Tacna. (2015). Exposición "Artesanía fina en caña hueca”. Tacna, Perú: Dirección de artesanías.

Egg, E. (1978). Introducción a las técnicas de investigación social. Buenos aires, Argentina: Hvmanitas.

INEI. (2000). Conociendo Tacna. Lima, Perú: Oficina técnica de difusión estadística y tecnología informática OTDETI.

Instituto Nacional de Recursos Naturales (2002). Recursos forestales. Tacna, Perú: Administración técnica forestal y de fauna silvestre ATFFS.

Instrumento Musical Paternity Aids Xiao (2004). Instrumentos musicales de caña. $\mathrm{R}$ e c u p e r a d o d e https://es.dhgate.com/product/wholesal e-children-39-s-handmade-diymusic/389718062.html.

Jabal, J. (1981). Botánica. Barcelona, España: Cultural, S.A. De Ediciones.

Los Planitos de LUPÍN (2017). Cometa de caña. Recuperado de

https://losplanitosdelupin.wordpress.co $\mathrm{m} / 2017 / 03 / 14 /$ contruccion-barrilete-decana-y-papel-mylar/

Mariategui, J. (1972). 7 ensayos de la interpretación de la realidad peruana. Lima, Perú:Amauta.

Margulis, L. \& Sagan, D. El proceso de nutrición de las plantas. Biología geológica.

Matos, J. (1976). Hacienda, comunidad y campesinado en el Perú. Lima, Perú: IEP ediciones.

Mota, B. (2014). Experiencias en el control y la erradicación de la caña (Arundo donax).

Municipalidad distrital de Ilabaya. (2007). Proyecto "Fortalecimiento de las capacidades para la produccion de 
artesania en caña en las localidades de mirave, chulibaya, poquera y chejaya del distrito de ilabaya-jorge basadretacna”. Tacna, Perú: Unidad formuladora - O.P.P.C.T.- M.D.I.

Odero, D. \& Ferrell, J. (2018). Giant Reed (Arundo donax): Biology, Identification, and Mana gement, University of Florida/IFAS Extension.

Panty, O. (2018). Tacna en la coyuntura de 19291934. La Vida y la Historia, 5(7), 34-55. https://doi.org/10.33326/2617604 1 . 2018.7

Pérez G. (2014). Los elementos de la forma en la arquitectura doméstica moqueguana. Revista De Arquitectura, 1(1), 51-72.
Reyes, M. (2003). Formación laboral: Agropecuaria y artesanía. Tacna, Perú: Universidad Inca Garcilaso de la Vega.

Tacna Fascinante (2019). Casa con techo tipo mojinete en el Pago Ayca. Recuperado $\mathrm{de}$

https://www.facebook.com/fascinanteta $\mathrm{cna} /$ photos/callejones-de-tacna-casacon-techo-tipo-mojinete-en-el-pagoayca/2217788871793723/

Turok, M. (1988). Cómo acercarse a la artesanía. México: Plazay Valdés.

Zubizarreta, A. (1991). La aventura del trabajo intelectual. Buenos aires, Argentina: Fondo Educativo Interamericano S.A. 